\title{
Loneliness among older people as a social problem: the perspectives of medicine, religion and economy
}

\author{
Werner Schirmer and Dimitris Michailakis \\ Journal Article
}

\section{Tweet}

N.B.: When citing this work, cite the original article.

Original Publication:

Werner Schirmer and Dimitris Michailakis, Loneliness among older people as a social problem: the perspectives of medicine, religion and economy, Ageing \&amp; Society, 2016. 36(8), pp.1559-1579.

http://dx.doi.org/10.1017/S0144686X15000999

Copyright: Cambridge University Press (CUP): HSS Journals

http://www.cambridge.org/uk/

Postprint available at: Linköping University Electronic Press

http://urn.kb.se/resolve?urn=urn:nbn:se:liu:diva-131665

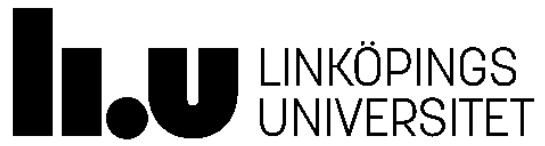




\title{
Loneliness among the elderly as a social problem:
}

\section{The perspectives of medicine, religion and economy}

\author{
By Werner Schirmer \& Dimitris Michailakis
}

Please cite as "Schirmer, Werner; Michailakis, Dimitris (2016). Loneliness among the elderly as a social problem: The perspectives of medicine, religion and economy. Ageing \& Society, Vol. 36 Issue 8, p1559-1579”

\begin{abstract}
This article offers a theoretical framework for studying loneliness among the elderly from a social problems perspective. The framework is a combination of the constructionist approach to social problems by Spector and Kitsuse and the theory of social systems by Luhmann. With the first we understand the social problem of loneliness among the elderly as the result of claims-making activities by different key actors. These activities are guided by cultural themes, images and causality constructions. With the second, we can explain how these claims-making activities are framed differently within different social systems. Due to their distinctive viewpoints social systems construct loneliness among the elderly in unique ways. Variations of meaning attributed to loneliness depend on the operative logic and the semantic stock of the respective social system. The argument of the article is illustrated with respect to three different social systems: medicine, religion and economy. In terms of underlying morality, causes and consequences, responsibilities and solutions loneliness among the elderly appears as something different from each of these perspectives: as a matter of health and illness, as a matter of spirituality, and a matter of incentives and commodities, respectively.

The value added of combining constructionism and systems theory for research on elderly and loneliness is to give justice to the non-objective, observer-dependent nature of social problems. The relevance for both researchers and practitioners working with loneliness
\end{abstract}


among the elderly on a policy-level is the increase of awareness of the multiperspectivity behind constructions of social problems. The failure of current intervention methods against loneliness is, at least partially, due to the lack of knowledge about the variation of (potentially contradictory) problem definitions of loneliness among the elderly. Ignoring this variation has practical consequences for the efficiency of possible measures against the social problem of loneliness.

\section{Keywords}

constructionism, economy, elderly, loneliness, medicine, religion, social problem, systems theory

\section{Introduction}

This article proposes to study loneliness among elderly people from a social problems perspective. Such a perspective understands social problems such as loneliness among elderly people as the result of claims-making activities which are guided by representations, concepts and images. Images of loneliness are produced within communicative contexts, and depending on context and perspective, these images differ.

Prevalence of loneliness among old people has been reported in many Western countries (Golden et al. 2009, Nyqvist et al. 2013, Tiikkainen and Heikkinen 2005, Victor, Burholt and Martin 2012). Loneliness is said to be problematic, first and foremost, because it increases their risk to mental and physical illness (Hawkley and Cacioppo 2007). Loneliness of elderly also puts pressure on their relatives. It burdens both the healthcare sector and the welfare services. On a societal level, loneliness among the elderly questions the strength of a society's value system and its sense for solidarity(Durkheim 2012[1893]).

Existing research on loneliness among the elderly mostly focuses on psychological and medical causes and on the consequences that loneliness has at the individual level. Based 
on a frequently used definition by Weiss (1973), many authors (Dahlberg and Mc Kee 2013, Liu and Rook 2013, Pettigrew and Roberts 2008, van Baarsen et al. 2001, Victor, Grenade and Boldy 2005) regard loneliness as a two-dimensional phenomenon: emotional loneliness (felt, perceived loneliness) and loneliness as social isolation, i.e. the feeling of having a too narrow social network. In both cases, loneliness is primarily seen as an individual experience, more a psychological problem than a social one. Typically, researchers are interested in why some individuals suffer from the experience of loneliness while others do not, and how lonely people suffer from it both emotionally and physically.

Roughly speaking, the findings in the literature can be divided into two main groups. The first one covers causes of loneliness, understood both as emotion and social isolation. Among the most important determinants researchers have found are loss of partner (Jylhä 2004, Victor et al. 2005), living alone (Nyqvist, Cattan, Andersson, Forsman and Gustafson 2013), lack of friends and social network (Peplau and Perlman 1982), ill health (Hawkley and Cacioppo 2007), handicap, both own or partner's (Alma et al. 2011, Korporaal, Broese van Groenou and van Tilburg 2008) as well as having an ethnic minority background (Victor, Burholt and Martin 2012).

In the other group of research findings, consequences of loneliness for the mental and physical wellbeing, and more generally, quality of life (Dykstra 2009) are highlighted. It has been shown many times that involuntary loneliness has negative effects on individuals' wellbeing. The most common effect is depression (Golden, Conroy, Bruce, Denihan, Greene, Kirby and Lawlor 2009, O'Luanaigh and Lawlor 2008), quite frequently leading to suicide ideation, particularly after the loss of a spouse (Eriksson and Svedlund 2007, O'Luanaigh and Lawlor 2008) but also a number of physical illnesses such as high blood pressure, cardiovascular illnesses, decreased cognitive functions and limited immune system have been singled out in research to be the resultants of loneliness (Cacioppo, Hawkley and Berntson 2003, Hawkley and Cacioppo 2007). 
In sum, the bulk of research on loneliness among the elderly has a clear focus on psychology or medicine. However, to our knowledge there is a lack of studies from a social problems perspective, i.e. a perspective that discusses how loneliness among the elderly is framed and communicated by various actors and in a variety of forums as a social problem. The classical literature on social problems has been dominated by the functionalist approach (Merton and Nisbet 1971), the value-conflict approach (Fuller and Myers 1941) and some variations of Marxist-inspired and critical conflict theories (Feagin 1986, Mills 1959). Despite obvious differences concerning theory architecture and conception of society, these approaches agree insofar as they consider social problems as objective conditions that are somehow at odds with central societal values (how things ought to be), have adverse effects for (parts of) the population or society as a whole, and can be alleviated by therapeutic or political interventions. Moreover, there is agreement that problems are social insofar as they are assumed to have social causes and/or social effects, and consequently there must be social solutions. Much of the contemporary literature shares this understanding (Alessio 2011, Dello Buono 2013, Glynn, Hohm and Stewart 1996, Horton et al. 1997).

With a "social problems perspective", however, we do not simply mean to assert that loneliness among the elderly is a social problem, i.e., that it needs to be understood as an objective condition with social causes and/or consequences. Drawing on the constructionist approach in the social problems literature (Best and Harris 2012, Loseke 2003, Spector and Kitsuse 1987 [1977]), we argue that there is always a "subjective nature of social problems", as Best (1995: 4) put it. Social problems are what particular key actors, so-called "claimsmakers" (Spector and Kitsuse 1987 [1977]) view as social problems. Claims-makers construct particular (putative) social conditions as problematic, violating widely shared values, harming particular groups of people, and in need of remedy.

Approaching loneliness among the elderly from a social problems perspective, then, means to study how the phenomenon is discovered, framed, judged, discussed, problematized 
and tackled by different key observers in society. The understanding of loneliness as a social problem always involves an empirical observer (i.e. an observer that itself can be observed) using some standards in order to verify loneliness. Due to differentials in various observers' social positions and functions they fulfil, one can expect a variety of different images of loneliness among the elderly as a social problem.

Furthermore, in order to study loneliness among the elderly from a social problems perspective, we argue that the constructionist approach as such is not sufficient and should be complemented with a theory of society. We suggest the theory of social systems by Niklas Luhmann (Luhmann 1995, Luhmann 2012, Luhmann 2013) which explains how different social systems - due to their distinctive viewpoints - construct objects within their range of observation differently. Regarding the study of social problems this view is highly relevant and adequate because it gives a theoretical account for the variations in how and why different key actors construct "loneliness as a social problem". In the next section this theory and the constructionist perspective will be explained in more detail.

A basic assumption for this article which follows from these frameworks is that there is not a single and for all actors same problem definition of loneliness among the elderly; instead there is a big variation of problem definitions. Despite the fact that such an approach is missing in the literature on loneliness among the elderly, there are some articles that either take up stances (at least partially) compatible with our proposed framework or present findings that are supportive of it. Some authors argue against the dominance of quantitative research in the literature that treats loneliness "in terms of linear and cause-effect relationships and prescriptive interventions" (Karnick 2005: 11), criticizing that loneliness mostly is regarded as a pathological or deficit condition (Graneheim and Lundman 2010, Rosedale 2007, Victor, Scambler and Bond 2009); they suggest the discussion of alternative notions of loneliness, drawing on Frankl's psychology and philosophy where loneliness is also seen as a phase of personal discovery and growth (Karnick 2005). In a similar vein, there are 
phenomenological studies of loneliness among the elderly examining "variations of lived experiences of loneliness" (Dahlberg 2007, Graneheim and Lundman 2010, Long et al. 2003). Furthermore the qualitative interview study be Stanley et al. (2010) needs to be mentioned because it not only accounts for variation among older adults' experiences of loneliness, it also introduces what systems-theorists call "multiperspectivity" as they show differences between the descriptions made by the elderly themselves and care personnel. The study that comes closest to what we here call a social problems perspective is the one by Uotila, Lumme-Sandt and Saarenheimo (2010), who explicitly analyse "loneliness among the elderly" as a social construction. Although not drawing on the constructionist approach by Spector \& Kitsuse etc., they emphasize how constructions of elderly persons' loneliness as a social problem are contingent on the social and cultural contexts, and how these constructions vary in terms of meanings, causes, and consequences (Uotila, Lumme-Sandt and Saarenheimo 2010: 109). Their focus is on mass media, treated rather as a forum for different societal actors (and commentators), than as a constructor in its own right (Luhmann 2000b). In our view, this leads them to emphasize too much the "themes" with which loneliness is connected, rather than analysing in a systematic manner which social actors rather tended to what problem definition of loneliness among the elderly. However, we agree with them that:

\footnotetext{
"it is important to know more about the construction of loneliness and identify all dimensions which are attached to it in our society. When loneliness in better understood and conceptualised, it would be also easier to build effective programmes aimed to relieving loneliness" (Uotila, Lumme-Sandt and Saarenheimo 2010: 124).
}

The insight from all of this research for a constructionist approach is not whether loneliness is a negative or positive experience but that there is variation in meaning and evaluation, particularly when taking different observer's points of view into account. This is less trivial than the assumption that there is wide variety of definitions, operationalization and measurements scales (such as the "de Jong Gierveld-scale and the UCLA-scale) as it points to the core structural characteristic of modern society. In our understanding modern society is 
horizontally differentiated in function systems; this implies that society has neither a top nor a centre from which universally valid and binding descriptions of whatsoever phenomenon could be provided.

In this article we want to provide a theoretical framework for the empirical study of how different social actors (observing systems, in Luhmann's terminology) construct loneliness among the elderly as a negative social condition that harms a certain amount of people, is at odds with widely shared societal values and requires socio-political countermeasures. On the basis of their different social positions and functions, interests and performances, it is reasonable to assume that different social actors understand and frame loneliness among the elderly as a social problem in differential ways regarding causes, consequences and solutions. As this article is of a theoretical nature, we offer empirical material only for the sake of illustrating our argument. We will discuss the views from three different societal function systems: medicine, religion and economy. As many observers point out there are tangible negative effects of loneliness on the physical and mental wellbeing and given the frequent references to health issues in research of all disciplines - it seems reasonable to take the medical point of view as a starting point. This perspective we want to contrast with constructions made from two other perspectives that at first sight seem less relevant (at least in the research literature) but have important tasks in society as a whole, and come to completely different views on loneliness among the elderly in terms of meanings, causes, consequences and solutions. These are the perspectives of economy and that of religion.

The article is structured as follows: Section 2 provides a detailed presentation of the theoretical framework. First, we elaborate on the constructionist approach in social problems theory; second, we introduce Luhmann's conceptualization of modern society being functionally differentiated in autonomous social systems; and third, we briefly discuss some implications of combining constructionism with Luhmann's theory of society. Section 3 
presents the viewpoints of the social systems medicine, religion and economy according to the Luhmannian theory and shows how this can be a starting point for the analysis of variations in the problem definitions of different observers regarding old people's loneliness. This section makes use of illustrations from empirical data. The concluding section discusses the benefits of the proposed framework to study loneliness among the elderly from a social problems perspective and its implications for research.

\section{A social problems perspective: Constructionism and systems}

\section{theory}

\section{Constructionism on social problems}

Despite their disagreements most constructionists endorse the proposition that the world cannot be experienced directly, and independent of an observer. Every observation implies selection and interpretation; observations do not represent but construct reality. Based on these assumptions the constructionist approach to social problems considers itself as a direct response to objectivist theories of social problems such as functionalism or critical theory as well as to positivist mainstream research on social problems. Constructionists argue that the latter often uses common-sense notions of social problems (Best 1995) when studying issues such as inequality, racism, homelessness, substance abuse, etc. Such notions start with the taken-for-granted assumption that there are objectively determinable social conditions which are somehow harmful to a specific group of people, that these conditions are somehow adverse and that they should be countered. The three mentioned approaches vary with respect to the justification of combating adverse social conditions, i.e. they differ from each other at the normative level. Thus, depending on the applied framework, social problems should be tackled either because they are a) harmful to society and social order (functionalism), b) injustices to the benefit of ruling classes (critical theories) or c) generally morally undesirable 
(mainstream). Objectivist approaches treat social problems as facts, thus they embark on measuring the magnitude of the problematic conditions as well as the determinants and consequences of these conditions.

By contrast, constructionism points out inherent methodological problems with any attempt to define a social problem in objective terms (see Spector and Kitsuse 1987 [1977]: 31ff). While there exists a large amount of potentially harmful conditions in society, only a limited number of these are given the status of social problems. Researchers need to ask under what circumstances some conditions receive the status of social problems while others do not. Constructionism therefore departs by asking how and by who is determined what counts as an adverse objective condition i.e. as a potential social problem. Constructivists argue that there are always interpretations and subjective evaluations involved which preclude a neutral, merely factual understanding of social problems (Best and Harris 2012). Objectivist approaches have difficulties in accounting for the normative standards from which problematic conditions deviate. One might question whose standards; based on which values; how are the harmed groups delimited; how is harm defined, etc.? While it is possible to give determined answers to these questions, it is impossible to do so in a universally valid way. Not only have certain conditions received or lost their status of a social problem in the course of time (Spector and Kitsuse 1987 [1977]) or the meanings of conditions have changed. There is, furthermore, "no necessary relationship between the measurable characteristics of any given condition or the people in it and a definition of that condition as troublesome" (Loseke 2003: 9). Most important for the argument of this article is the circumstance that different people, groups, and social systems (e.g. politics, science, or medicine) might make different judgments on what counts as a problem. Against this background, constructionists give up the idea of looking for objective conditions of social problems.

As a consequence constructionists argue that for social problems to exist socially, people first need to recognize and define them as such and help the definition to enjoy 
widespread recognition (Best and Harris 2012, Loseke 2003, Spector and Kitsuse 1987 [1977]). As Loseke puts it: "Conditions might exist, people might be hurt by them, but conditions are not social problems until humans categorize them as troublesome and in need of repair" (Loseke 2003: 14). Therefore, constructionists focus on the social activities that render any (putative) social condition into a social problem in the first place. Spector and Kitsuse, the "founding fathers" of this approach, speak of social problems as the result of "claims-making activities" (Spector and Kitsuse 1987 [1977]: 75f). Claims-makers - for instance movements, professional associations, interest groups - point out putative social conditions as violating ethical standards or other shared values, concern or harm certain groups, and require counter-measures. As a rule, there are several claims-makers competing with each other for interpretative primacy and scarce attention of audiences (supporters as well as policy-makers).

One key insight of constructionism is that different claims-makers typify social problems differently. Not only do they use different arenas, different strategies and rhetoric to persuade their audiences (Best 1995: 350). More importantly, claims-making activities vary along four dimensions or parameters. First, constructions of social problems vary in terms of the causes and conditions: what is portrayed as wrong/bad, what is part of the problem, what is excluded, what are the deemed causes of the condition? Second, problem constructions address cultural themes, i.e. conditions violating widely shared values. The variable here is the underlying morality within which the putative condition appears as a reason for indignation. Third, claims-makers vary in their construction of people as victims and villains. Victims are those who suffer unfairly from the condition, are not responsible and deserve sympathy. Villains deserve condemnation, as they are held responsible for the condition; these do not need to be persons but can also be institutions, social structures or social forces. Fourth, problem constructions vary in terms of the proposed or demanded solutions, thus a line of action based on parameters 1 and 2 (underlying causal schemes and moralities) which 
legitimizes certain solutions (while excluding others) and which holds certain people or organizations responsible for providing these solutions.

\section{Theory of social systems}

Luhmann's theory is a very complex framework comprising several building blocks such as theory of communication, general theory of social systems, theories of interaction systems, organizations, and not least, a theory of modern society. The latter is of particular interest for our argument, despite the fact that it consists of various building blocks (evolution, differentiation, communication, self-descriptions; for an overview see Lee 2000). Most important here is Luhmann's analysis of modern society as the differentiated unity of major social systems. Examples are the systems of politics, law, economy, science, religion, education, medicine, mass media, families, etc. Because each of them fulfils a unique and necessary function for society as whole Luhmann (2013) calls them function systems. The term function refers to the circumstance that these systems provide solutions to particular reference-problems (Bezugsprobleme). For example, science solves the problem of providing reliable knowledge to society; politics the problem of taking decisions that are collectively binding and enforcing them, economy the problem of allocating scarce resources, law the problem of stabilizing mutually conflicting expectations, etc. A paramount characteristic of function systems is that their operations centre on the fulfilment of their function, thereby observing and interpreting everything that falls into their field of vision in a particular, function-specific way. For example, the legal system observes any social event in terms of its conformity or violation to currently valid laws; from the viewpoint of the legal system, any event, be it a simple everyday action, a business trade, or a scientific study, is rendered into a matter of legality/illegality: are laws violated, contracts breached, frauds committed? Likewise, from the perspective of science, the everyday action, the trade, and the study become a potential research object accessible with theories and methods. Similar statements 
apply to the other function systems (Section 3 will deal more extensively with the three function systems medicine, religion and economy).

In this regard, the perspectives of function systems are total but not universal: they can deal with any social event or thing, but there is always a multiplicity of other perspectives available from which the very same thing/event appears differently. As Luhmann argues, this multiplicity of function-system perspectives constitutes the structure of modern society which Luhmann describes as functional differentiation: a horizontal structure of coequal social systems within which none is more or less important, dominant or central than the others. In other words, modern society lacks both a centre and a top that pre-modern stratified societies had.

The consequences of this analysis of modern society for our purposes of studying the loneliness among elderly people, as a social problem is obvious: there is no privileged position/social system that can define in a manner universally valid and binding for everybody how loneliness among the elderly is supposed to be understood. Not politics, not medicine, not science, nor any other system can do so because the same reference object is constituted, i.e. constructed differently contingent of the observing perspective.

\section{Combing constructionism and systems theory}

The constructionist approach to social problems helps us shifting the focus from (whatever) objective conditions of social problems toward the communicative activities of social actors that aim to point out putative social conditions as violations of the normative order, and in need of alleviation. Especially in regard to the four parameters of conditions/causality, cultural themes (moralities), people (victims/villains), and solutions, the constructionist approach provides a framework for the empirical study of social problems. However, it lacks a theory of society that can explain on the societal level why some actors construct social problems in particular ways while other actors construct them in different ways. What are the 
societal prerequisites for these different constructions? Following Luhmann's theory of functionally differentiated society, we assume a society that consists of a multiplicity of observing systems, each equipped with a distinctive perspective. In that way, we can give accounts for the social locus of particular claims-makers contingent on function-systemic background from which they raise their claims. As we will illustrate in the next section with the perspectives from medicine, religion and economy, the problem constructions of loneliness among the elderly will differ not only in terms of the four parameters provided by constructionism but also in line with function-systemic perspectives. We argue that the combination of the constructionist approach and Luhmann's systems theory leads to a fruitful framework to study variations in claims-making on loneliness among the elderly as a social problem and at the same time give structural explanations on why certain claims-makers frame the conditions, causes, solutions and involved people in the way they do. Combining the two approaches into one framework helps us to see that each of the involved key actors (claims-makers) represents speaker roles of particular social systems (AUTHOR; AUTHOR). Each of them has a genuine observational perspective, rationality and interest to have the social problem defined in a certain manner.

\section{Three perspectives on loneliness among the elderly}

In this section we illustrate our argument with three systematically different views on older people's loneliness as a social problem, namely the function-systems perspective of medicine, religion and economy. Each subsection begins with a short description of Luhmann's theory

of the respective system, then proceeds to develop the argument by providing excerpts from our empirical data (documents and in-depth interviews), and ends with an analysis of the excerpts from the proposed social problems perspective. The presented empirical examples have the purpose of illustration. They were chosen because they demonstrated the different function-systemic logics in a more ideal-typical way than most claims-making texts. 
Researcher need to be aware that the applied logics are not always as straight forward so more in-depth text analysis will be necessary for excavating the underlying rationalities when examining how loneliness among the elderly is constructed as a social problem.

\section{Medicine}

It seems reasonable to us to start with the viewpoint of medicine, because many contemporary problem descriptions of loneliness mention the latter's association with health issues. From a Luhmannian view, the system of medicine reproduces itself by means of communications related to health and illness (Luhmann 2005). In contrast to other systems which include persons as citizens, pupils, buyers, etc. into their systemic operations, medical communication addresses persons as patients. Therefore, they mostly become relevant as bodies (Saake 2003), and only insofar as their condition is judged as a pathological deviation from predefined states (defined as health) on bio-physiological and/or behavioural-psychological levels. The main focus of medical observations is on the individual (with the exception of epidemiology) but it becomes a matter for the collective level when non-medical (e.g. political, financial, legal) constraints hamper the execution of medical operations (such as in the case of healthcare priority setting; Schirmer \& Michailakis, 2011), or when the occurrence of illnesses is attributed to social causes and future illness needs be prevented. Particularly in the latter cases can be a matter for social problems construction. We can expect that social problems constructed within the context of the medical system have a clear reference to illness, be it illness as an effect of social causes, illness as cause of social problems or problems or restrictions of the medical system due to societal causes. The following excerpt, taken from a blog posted by medical doctor, illustrates how loneliness among the elderly is framed as a social problem from the medical perspective:

\section{Excerpt 1}


Nearly 1 in 7 American adults are living alone and this isolation may provide additional stressors such as depression, anxiety and additional economic pressures. These stressors certainly may contribute to cardiovascular events in susceptible patients. Moreover, social isolation has been associated with changes in health behavior and access to care among patients. Patients who live alone may be less likely to seek care for recurrent symptoms and may not be compliant with drug therapy or other medical recommendations without support. [...] Our patients today are sicker and have more limited resources. Financial pressures are forcing physicians to tackle larger clinic schedules with overall increased workload demands. But, as providers of health care, we must assess social isolation and loneliness in our patients. We must identify “at risk” patients and make attempts at intervention. Since these studies suggest that living alone is an independent prognostic factor for mortality and CV disease, clinicians must work to counsel their patients about seeking appropriate medical attention when needed and, in appropriate cases, refer patients to programs with psychological intervention. Many of these patients have no families, no adult children and no support group. In these cases, we must do our best to fill in the gaps (yes, all in a busy office full of patients). Healthcare costs in the US continue to skyrocket and there are no easy fixes in the works. I believe that a simple, although potentially time consuming, intervention such as talking with lonely and socially isolated patients when they are in the office for a visit, is a low cost preventative measure. By taking time to hold a lonely patient's hand, we may potentially make a positive impact. Data such as those presented in the Archives this month certainly point out the risks of loneliness and suggest that patients without social support in place do very poorly and develop significant cardiovascular illness.

(Loneliness and The Elderly: Dying of a Broken Heart, Posted by Dr. Kevin Campbell

http://ncheartvascular.com/loneliness-and-the-elderly-dying-of-a-broken-heart/

As explained earlier, social problems refer to conditions that violate core social values, have a defined group of victims suffering from certain conditions and possible solutions to remedy these conditions. Typically for a perspective from the function system medicine, the problem is constructed as a matter of health and illness. Accordingly, lonely elderly are portrayed as victims of the condition, but particularly in terms of the negative effects for their health. To be precise, at the core of the problem are the negative medical consequences. The societal value at stake is the right to be healthy and free from harm. Typically for claims-making in order to 
amplify its case, the text establishes a clear-cut causality by drawing on research data which suggests that lonely people suffer not only from loneliness itself and the direct detrimental consequences for their health (especially cardiovascular illness) but they adopt lifestyles that are more prone to ill health. In terms of solutions, the causality is straightforward: Loneliness needs to receive medical attention; if the problem is untreated, lonely people will suffer from diseases or die. Accordingly, this claims-making addresses the medical profession as target group who is portrayed as the responsible force to provide solutions and fight the consequences of loneliness, respectively. The proposed solutions are typically in line with the tasks of the medical profession, namely the identification of at-risk persons, counselling and medical treatment where appropriate.

\section{Religion}

From a modern, rational and secular point of view, religion might have lost the powerful position as the central instance of legitimation, social integration, and solidarity that it had until the end of the middle-ages in Europe. However given the millions of people who are members of religious associations or believe in supra-natural powers, and the role that religious congregations play in civil-societal movements, it would be premature to lose religious viewpoints out of sight when studying social problems. In the course of sociocultural modernization and rationalization and the shift to functional differentiation as the primary structure of society, the descriptions of other newly autonomous function systems (in particular science, politics, economy and arts) had started to challenge the religious monopoly of explaining and justifying the world. During this process of mutual competition and struggles over meanings, the societal function of religion also sharpened, maintaining the primacy of distinct view on the world that no other function system can offer: the relation between immanence and transcendence (Luhmann 1977). This relation refers to inherent paradoxes of modern society to which religion offers answers: explanations of the 
unexplainable, observations of the unobservable, definitions of the indefinite, the meaning behind the seemingly meaningless, and the meaning behind meaningfulness. Therefore the religious system is more ambiguous and nebulous than other function systems (Beyer 1998: 98). Central in all religious communication is the reference to something beyond, something transcendent, be this a God, a spirit, a force, the sacred. This "something" beyond is definite, and only therefore is the source of all meaning in an indeterminate immanent world (Laermans and Verschraegen 2001). Things and events in the immanent world acquire a religious meaning when viewed from transcendence (Luhmann 2000a), that is, from an external observer that can observe the entity as entity, just something that is not possible from an immanent, this-worldly perspective. As for loneliness among the elderly, we can expect religious viewpoints constructing it as problem of the relation between immanence and transcendence as well as searching interpretations, guidelines, explanations and solutions in light of transcendental forces. The excerpt below shows a religious view on loneliness as a social problem.

\section{Excerpt 2}

Yet for others longing to be with brethren, the lack of handshakes and fellowship can take its toll, sowing the seeds of loneliness. When allowed to germinate, these seeds can sprout into feelings of discouragement, and will eventually mature into a state of despondency. [...] This becomes a fertile field for Satan to sow seeds of doubt and a perfect climate for his negative influence. Satan preys on the lonely, who are perhaps his easiest victims. You can be sure he will take every opportunity to heap on more negative thoughts until he has the person so "down in the dumps" that he or she will want to quit altogether. This is at least a part of the reason God intended we all have Christian fellowship. [...] We must realize that although human fellowship is important in combating loneliness, it is not the most important. The apostle John wrote, "That which we have seen and heard we declare to you, that you also may have fellowship with us” (I John 1:3). John wanted the brethren to have fellowship with one another, but notice the primary stress: "And truly our fellowship is with the Father and with His Son Jesus Christ.” Without contact with God, you might have friendships, but not true Christian fellowship. Our spiritual closeness with God guarantees that our contact with each other will be profitable and edifying. No human or group of humans can substitute for contact with God. Many of us might like to see our needs met by 
other humans from what is termed "the human connection.” But the human connection is not enough. Simply stated, we cannot and will not be close to each other as members of the Body of Christ unless we are first close to God! As we draw closer to Him, we will inevitably draw closer to each other. Conversely, when we drift away from God we will find ourselves forsaking each other. Recognize that our first line of defense against loneliness and every other negative emotion is our personal contact with our Creator. Fellowship with God is the best kind there is.

http://rcg.org/pillar/0801pp-btsol.html

This excerpt is taken from a Christian blog discussing loneliness and the way out of it. In a passage not in the above excerpt, the text mentions a couple of social causes to loneliness, such as changes in family structures, values and lack of intergenerational contacts, as well as medical and bio-psychological causes. While acknowledging mainstream views on loneliness as a social problem, the text is interesting for our purpose insofar as there is a genuinely religious way of addressing consequences of loneliness and solutions to it. Loneliness is said to put people at risk for influence by the Devil. Depression and suicide are presented as the work of the Devil pushing "dark thoughts" on the lonely. The proposed solution to loneliness is then seemingly simple: a Christian fellowship, which is a community with God, protects against the dark thoughts lonely people get implanted by the Devil. A community with God not only dissolves the individual experience of loneliness but at the same time, albeit more implicit, also wipes out loneliness as a social problem: if people are more inclined to find a way to God, they will find a way to each other. The underlying causal logic is like this: although loneliness can be triggered by different (social, medical, etc.) factors, the cause of it is lack of contact with God. Accordingly, contact with God is the supreme action plan to get out the misery because it will enable contact to other human beings as a consequence. The perspective on loneliness in this excerpt makes only sense in a religious contexture, i.e. a social system for which the distinction between the immanent, this-worldly realm and the transcendent realm where entities such as God and the Devil prevail is central. The latter exert 
forces beyond human control and understanding, and, one of them, the evil one, can only be countered by submitted to the other, i.e. the good one. Therefore, the community with God (with God one is never lonely) is seen as superior to this-worldly human fellowship.

\section{Economy}

With the exception of the protestant ethic pointed out by Weber (2009[1904]), religions always had a problem with economics as an end in itself. In this regard, the perspective of the economic system can be understood as a counter-view to religion which can focus on the sinfree accumulation of wealth in an immanent world without any regard to transcendence.

For the economic perspective the world appears as a space full with commodities to be bought and sold at the right price. People, things and events become relevant in terms of investments, profits and losses, gains and costs. The societal function of the economic system is the provision and allocation of future resources under the conditions of scarcity, and this is accomplished with a differentiated self-referential system of exchanges based on money (Luhmann 1988). We can expect that loneliness among the elderly is portrayed as a matter of costs, particularly for the public sector, but also as a market for businesses.

\section{Excerpt 3}

Perhaps it's time to review our obsession with keeping older people "independent” and our fetish about "keeping people in their own homes”. Now don't get me wrong, I am not recommending a return to the era of asylums for people who can't cope on their own. Nor should anyone who wishes to remain independent and on their own be prevented from doing exactly that, if it suits them. [...] What I am saying is that, as a society, we have insisted that everyone should have a little box to call their own, be they a young single mother, a professional so-called "first-time buyer", and even vulnerable or elderly members of our society whose needs are met by "care in the community". We ensure that these people have a roof over their head and their physical needs are met, but we seem to be missing out on the better quality of life that having a shared living space can bring for those who want or need it. [...] A start would be a reform of the taxes [...] that affect families when two generations live together. At present, if an older person sells their home and gives the money to a younger family member so that 
the two generations can buy a home together, there may be either inheritance tax implications under the "gift with reservation of benefit” rules or an income tax liability under pre-owned assets rules or both, depending on the arrangement. The reason is that the older person who makes the gift is treated as if they haven't given the money away, because they are still enjoying the proceeds of a purchase made with it. Similarly, an older person cannot give away their home tax-free to a son or daughter who moves in with them to care for them, because in this case they continue to live in the house alongside them, benefiting from the asset that they have intended to give away. This must be a huge disincentive to the generations living together. Why would you want to give up your own home to move in with Granny, only to find yourself hit with a bill for inheritance tax when Granny passes away, potentially leaving you homeless if you now need to sell the house you live in to pay the bill? https://www.saga.co.uk/money/experts/could-inheritance-tax-reform-help-combat-loneliness.aspx?pid=mn

\section{Excerpt 4}

Many seniors would like to have a partner of their hearts who provides emotional support. Being old does not necessarily mean loneliness. Dating for 50plussers can mean that you meet people who lead their lives actively and open-mindedly. Your career is on its climax. Alone, sports, culture, travelling are of course only half the fun. The familiarity of partnership and the talking are missing - the joint experience makes our life richer and nicer. [...] Loneliness verifiably shortens the life. Those who live in a steady relationship live longer. Love makes our life simultaneously richer and simpler, as science confirms. Successful couples are strong teams that can counter the adversities of life. Grant yourself this attitude to life! Together against the rest of the world is a goal which you can achieve with our First Partner Forum for Seniors. https://www.partnerforum-fuer-senioren.de/vorteile.aspx

Excerpt 3 starts out as a critique of current society which is said to put pressure on people to live their own while disregarding the loss of life quality that goes along. Elderly's loneliness needs to be seen in this context. In this example of claims-making it is clearly seen as a social problem, and it is an undesired outcome of wrong incentives posed by faulty tax rules. Because with the tax system families get financially punished when elder parents sell their house and bequeath or present their children with the revenue, it seems more rational to let the elderly keep their own home and lead separate households. The result is lonely elders. In other 
words, loneliness is a consequence of families saving money; it can be combated with a revised tax system that promises higher payoff when moving together. Loneliness among the elderly is framed in terms of economic causes and economic solutions and as an outcome of people living in economically rational ways. The addressee of the claim, however, is the government which is institutionally responsible for changes in tax laws.

Considering excerpt 4 as an example of claims-making in terms of social problems might seem a bit odd at first sight because it is actually an advert text of a dating agency for people beyond 50. However, advert texts work in way structurally very similar to claims-making: pointing out a problem in need of remedy, make use of science to increase respectability, using simplified causalities and exaggerations as well as call for actions and solutions. The difference is (similar to political claims-making, see Michailakis \& Schirmer 2014, Schirmer 2008), that the authors portray themselves as the solution to the problem, and the claim to action is directed to the reader. Although economic concepts and words (such as costs, price, market) are completely absent in the excerpt, the logic is clearly an economical one. The offer would not make sense without the logic of demand and supply, commodities, customers with needs and suppliers selling the commodity. The customer is the lonely elderly, if not already suffering from loneliness then attempted to be convinced by the advert that his/her life could be so much better, thereby amplifying the need. Naturally, the agency is the supplier of the commodity fulfilling this need, while the unquestionable fact that the customer has to pay for the supply is kept tacit. This kind of text is claims-making because of its clear causality and demand for action. In contrast to much of other social problems claims-making, the addressee is not the welfare state but of course the customer who has to do something. The message to the lonely person is clear: all you have to do is join us, and we will provide you with what you seek, namely love and togetherness. From a social problems perspective it is interesting to see 
how private enterprises benefit from loneliness among the elderly by amplifying and exploiting a need and themselves acting up as the solutions to the problem.

\section{Conclusion}

In this article we have tried to give a theoretical account for how and why the social problem of loneliness among the elderly is constructed in different ways by different observers. Drawing on the theory of social systems by Niklas Luhmann and the constructionist approach to social problems, we argued that the "same" issue is brought into existence i.e. made meaningful differently by different function systems. According to the constructionist stance there is no true description of loneliness to which everybody must agree. This is a consequence of the condition in modern society. Different actors and function systems create their own descriptions of reality. The validity and accuracy of these descriptions cannot be judged with standards from other systems (see Schirmer \& Michailakis 2011). Every function system processes "meaning” according to its own semantic stock. It is the logic of the particular system that determines the meaning the particular phenomenon receives. Thus, loneliness as a social problem becomes meaningful in different ways for different function systems, as we demonstrated with religion, economy and medicine.

The content of our argument has implications both for research and policy. It was pointed out by others that research on intervention methods against loneliness hardly shows promising results (Cattan et al. 2005, Findlay 2003, Savikko 2008). It is reasonable to assume that the failure of intervention methods is, at least partially, due to the lack of knowledge about this variation of (potentially contradictory) problem definitions of loneliness among the elderly. Ignoring this variation has practical consequences for the efficiency of possible measures against the social problem of loneliness. Both researchers and practitioners working with elderly or deal with loneliness among the elderly on a policy-level need to be aware of the multi-perspectivity behind constructions of social problems: Whose description is it? On 
which criteria (values, causalities, expectations) is it based? What would be the implications for solutions or accountability claims when building a particular intervention method or policy program on a particular problem-description? How would this look like when taking a different problem description as basis? As other researchers noted, there is a so-called "social problems industry" (Loseke 2003: 31, for the case of loneliness, see Uotila, Lumme-Sandt and Saarenheimo 2010: 123) that has a vested interest in promoting a certain problem definition of loneliness among the elderly that excludes or ducks others. Maybe the extent of loneliness is smaller than proclaimed by some claims-makers (Dykstra 2009, Schnittker 2007, Wenger and Burholt 2004)? Claims-making is part of a power struggle over definitions and the severity of a certain problem. Researchers, practitioners and policy-makers blind for the multiperspectivity of the different involved key actors will miss a major part and will produce flawed results or detrimental interventions.

\section{References}

Alessio, J. 2011. Social Problems and Inequality. Ashgate, Burlington.

Alma, M., Van der Mei, S., Feitsma, W.N., Groothoff, J., Van Tilburg, T. and Suurmeijer, T. 2011. Loneliness and Self-Management Abilities in the Visually Impaired Elderly. Journal of Aging and Health, 23, 5, 843-861.

Best, J. (ed) 1995. Images of Issues: Typifying Contemporary Social Problems. Aldine de Gruyter, New Brunswick.

Best, J. and Harris, S. (eds). 2012. Making Sense of Social Problems: New images, new issues. Lynne Rienner, Boulder.

Beyer, P. 1998. Globalizing Systems, Global Cultural Models and Religion(s). International Sociology, 13, 1, 79-94.

Cacioppo, J., Hawkley, L. and Berntson, G. 2003. The Anatomy of Loneliness. Current Directions in Psychological Science, 12, 3, 71-74.

Cattan, M., White, M., Bond, J. and Learmouth, A. 2005. Preventing social isolation and loneliness among older people: a systematic review of health promotion interventions. Aging and Society, 25, 1, 41-67.

Dahlberg, K. 2007. The enigmatic phenomenon of loneliness. International Journal of Qualitative Studies on Health and Well-being, 2, 195-207.

Dahlberg, L. and Mc Kee, K.J. 2013. Correlates of social and emotional loneliness in older people: evidence from an English community study. Aging \& Mental Health.

Dello Buono, R. 2013. Time to Change the Subject: A New Sociology of Praxis. Critical Sociology, 39, 6, 795-799.

Durkheim, E. 2012[1893]. The Division of Labor in Society. Martino Fine Books, Eastford. 
Dykstra, P. 2009. Older Adult Loneliness: Myths and Realities. European Journal of Ageing, 6, 91-100.

Eriksson, M. and Svedlund, M. 2007. Elderly Spouses Experiences In Connection With Their Partners’ Death: A Literature Review. Vård i Norden, 27, 1, 43-46.

Feagin, J.R. (ed) 1986. Social Problems: A Critical Power-Conflict Perspective. PrenticeHall, Englewood Cliffs.

Findlay, R. 2003. Interventions to reduce social isolation amongst older people: where is the evidence? Aging and Society, 23, 5, 647-658.

Fuller, R. and Myers, R. 1941. Some aspects of a theory of social problems. American Sociological Review, 6, 2, 24-32.

Glynn, J., Hohm, C. and Stewart, E. 1996. Global social problems. HarperCollins College Publishers, New York.

Golden, J., Conroy, R., Bruce, I., Denihan, A., Greene, E., Kirby, M. and Lawlor, B. 2009. Loneliness, social support networks, mood and wellbeing in community-dwelling elderly. International Journal of Geriatric Psychiatry, 24, 694-700.

Graneheim, U. and Lundman, B. 2010. Experiences of loneliness among the very old: The Umeå 85+ project. Aging \& Mental Health, 14, 4, 433-438.

Hawkley, L. and Cacioppo, J. 2007. Aging and Loneliness. Downhill Quickly? Current Directions in Psychological Science, 16, 4, 187-191.

Horton, P., Leslie, G., Lawson, R. and Horton, R. 1997. The sociology of social problems. Prentice Hall, Englewood Cliffs NJ.

Jylhä, M. 2004. Old Age and Loneliness: Cross-sectional and Longitudinal Analyses in the Tampere Longitudinal Study on Aging. Canadian Journal of Aging, 23, 2, 157-168.

Karnick, P. 2005. Feeling Lonely: Theoretical Perspectives. Nursing Science Quarterly, 18, 1, 7-12.

Korporaal, M., Broese van Groenou, M. and van Tilburg, T. 2008. Effects of Own and Spousal Disability on Loneliness Among Older Adults. Journal of Aging and Health, 20, 3, 306-325.

Laermans, R. and Verschraegen, G. 2001. 'The Late Niklas Luhmann' on Religion: An Overview. Social Compass, 48, 1.

Lee, D.B. 2000. The Society of Society. The Grand Finale of Niklas Luhmann. Sociological Theory, 18, 2, 320-330.

Liu, B. and Rook, K. 2013. Emotional and social loneliness in later life: Associations with positive versus negative social exchanges. Journal of Social and Personal Relationships.

Long, C., Seburn, M., Averill, J. and More, T. 2003. Solitude Experiences: Varieties, Settings, and Individual Differences. Personality and Social Psychology Bulletin, 29, 578-583.

Loseke, D. 2003. Thinking about social problems. Aldine Transaction, Hawthorne, NY.

Luhmann, N. 1977. Die Funktion der Religion. Suhrkamp, Frankfurt/Main.

Luhmann, N. 1988. Die Wirtschaft der Gesellschaft. Suhrkamp, Frankfurt/Main.

Luhmann, N. 1995. Social Systems. Stanford University Press, Palo Alto.

Luhmann, N. 2000a. Die Religion der Gesellschaft. Suhrkamp, Frankfurt/Main.

Luhmann, N. 2000b. The Reality of the Mass Media. Stanford University Press, Stanford CA.

Luhmann, N. 2005. Der medizinische Code. In Luhmann, N. (ed), Soziologische Aufklärung 5. VS Verlag, Wiesbaden, 176-188.

Luhmann, N. 2012. Theory of Society. Volume 1. Stanford University Press, Palo Alto.

Luhmann, N. 2013. Theory of Society. Volume 2. Stanford University Press, Palo Alto.

Merton, R.K. and Nisbet, R. (eds). 1971. Contemporary social problems. Harcourt Brace Jovanovich, New York.

Michailakis, D. and Schirmer, W. 2014. Social work and social problems: a contribution from systems theory and constructionism. International Journal of Social Welfare, 23, 4, 43142. 
Mills, C.W. 1959. The Sociological Imagination. Oxford University Press, New York.

Nyqvist, F., Cattan, M., Andersson, L., Forsman, A.K. and Gustafson, Y. 2013. Social Capital and Loneliness Among the Very Old Living at Home and in Institutional Settings: A Comparative Study. Journal of Aging and Health, 25, 6, 1013-1035.

O'Luanaigh, C. and Lawlor, B. 2008. Loneliness and the health of older people. International Journal of Geriatric Psychiatry 23, 1213-1221.

Peplau, L.A. and Perlman, D. (eds). 1982. Loneliness: A sourcebook of current theory, research, and therapy. Wiley, New York.

Pettigrew, S. and Roberts, M. 2008. Addressing loneliness in later life. Aging \& Mental Health, 12, 3, 302-309.

Rosedale, M. 2007. Loneliness: An Exploration of Meaning. Journal of the American Psychiatric Nurses Association, 13, 4, 201-209.

Saake, I. 2003. Die Performanz des Medizinischen. Zur Asymmetrie der Arzt-PatientenInteraktion. Soziale Welt, 54, 4, 429-459.

Schirmer, W. 2008. Bedrohungskommunikation. Eine gesellschaftstheoretische Studie zu Sicherheit und Unsicherheit [Threat Communication. A Sociological Study of Security and Insecurity]. VS-Verlag, Wiesbaden, Germany.

Schirmer, W. and Michailakis, D. 2011. The responsibility principle. Contradictions of priority-setting in Swedish healthcare. Acta Sociologica, 54, 3, 267-82.

Savikko, N. 2008. Loneliness of Older People and Elements of an Intervention for its Alleviation. In Department of Nursing Science. University of Turku, Turku.

Schnittker, J. 2007. Look (Closely) at All the Lonely People Age and the Social Psychology of Social Support. Journal of Aging and Health, 19, 4, 659-682.

Spector, M. and Kitsuse, J. 1987 [1977]. Constructing social problems. de Gruyter, Hawthorne NY.

Stanley, M., Moyle, W., Ballantyne, A., Jaworski, K., Corlis, M., Oxlade, D., Stoll, A. and Young, B. 2010. 'Nowadays you don't even see your neighbours': loneliness in the everyday lives of older Australians. Health and Social Care in the Community, 18, 4, 407-414.

Tiikkainen, P. and Heikkinen, R.-L. 2005. Associations between loneliness, depressive symptoms and perceived togetherness in older people. Aging \& Mental Health, 9, 6, 526534.

Uotila, H., Lumme-Sandt, K. and Saarenheimo, M. 2010. Lonely older people as a problem in society - construction in Finnish media. International Journal of Ageing and Later Life, 5, 2, 103-130.

van Baarsen, B., Snijders, T., Smit, J. and van Duijn, M. 2001. Lonely but Not Alone: Emotional Isolation and Social Isolation as Two Distinct Dimensions of Loneliness in Older People. Educational and Psychological Measurement, 61, 1, 119-135.

Victor, C., Grenade, L. and Boldy, D. 2005. Measuring loneliness in later life: a comparison of differing measures. Reviews in Clinical Gerontology, 15, 1, 63-70.

Victor, C., Scambler, S. and Bond, J. 2009. The Social World of Older People. Understanding Loneliness and Social Isolation in Later Life. Open University Press, New York.

Victor, C., Scambler, S., Bowling, A. and Bond, J. 2005. The prevalence of, and risk factors for, loneliness in later life: a survey of older people in Great Britain. Ageing and Society, 25, 6, 357-375.

Victor, C.R., Burholt, C.R. and Martin, W. 2012. Loneliness and Ethnic Minority Elders in Great Britain: An Exploratory Study. Journal of Cross Cultural Gerontology, 27, 65-78.

Weber, M. 2009[1904]. The Protestant Ethic and the Spirit of Capitalism. Norton, New York.

Weiss, R. 1973. Loneliness: The experience of emotional and social isolation. MIT Press, Cambridge, MA. 
Wenger, G.C. and Burholt, V. 2004. Changes in Levels of Social Isolation and Loneliness among Older People in a Rural Area: A Twenty-Year Longitudinal Study. Canadian Journal on Aging, 23, 2, 115-127. 